\title{
Development of Double Cloth Structure to Facilitate Versatile Application of Denim Fabric
}

\author{
Rubel Alam ${ }^{*}$, Tarikul Islam², Ahsan Haider ${ }^{3}$, Nazmul Haque ${ }^{4}$, Jahidul Islam5, \\ Mohammad Zakaria ${ }^{5}$
}

\author{
${ }^{1}$ Department of Knitwear Manufacturing and Technology, BGMEA University of Fashion and Technology (BUFT), \\ Dhaka, Bangladesh \\ ${ }^{2}$ Department of Textile Engineering, Jashore University of Science and Technology (JUST), Jashore, Bangladesh \\ ${ }^{3}$ Envoy Textiles Limited, Gazipur, Bangladesh \\ ${ }^{4}$ Amber Denim Mills Limited, Gazipur, Bangladesh \\ ${ }^{5}$ Department of Textile Engineering, Dhaka University of Engineering and Technology (DUET), Gazipur, Bangladesh \\ Email: *rubel@buft.edu.bd, matarikul.islam2014@gmail.com, ahsanhaidar2014@gmail.com, nazmulhq@gmail.com, \\ jimtex072@gmail.com,zakariate@duet.ac.bd
}

How to cite this paper: Alam, R., Islam, T., Haider, A., Haque, N., Islam, J. and Zakaria, M. (2019) Development of Double Cloth Structure to Facilitate Versatile Application of Denim Fabric. Journal of Textile Science and Technology, 5, 19-26. https://doi.org/10.4236/jtst.2019.51002

Received: October 24, 2018 Accepted: February 23, 2019

Published: February 26, 2019

Copyright $\odot 2019$ by author(s) and Scientific Research Publishing Inc. This work is licensed under the Creative Commons Attribution International License (CC BY 4.0).

http://creativecommons.org/licenses/by/4.0/

\begin{abstract}
Denim is the most popular dress material to any age of people. Day by day its demand increasing swiftly because of western life style and fashion has been accelerated with the trends of casualization across the globe. Nowadays, the present structure of denim (regular, stretch) cannot cover the versatile field of human needs owing to its comfort and stiffness problem. So it is very important to diversification of denim fabrics according to the customers demand and also acquisition the consumer. The main goal of the study is to develop double cloth structure in denim using $30^{\mathrm{s}} / 1$ and $20^{\mathrm{s}} / 1$ cotton (CW) yarn by some selected structures. Moreover, it will create new era by promoting versatility keeping with comfort factors. Here, some denim fabric has been manufactured by using double cloth structure that will give versatility and it affects thermo-physiological comfort. The warmth of a fabric has been found due to the trapping air into the structure and such applications like top garments, baby and kids wear, jacket, coat, cloth for winter season etc. Eventually, the samples have been tested and compared with regular denim on the basis of visual appearance, GSM, tensile strength, shrinkage and stiffness. The developed samples provided satisfactory level compared to regular. Most importantly, findings come due to dissipation the yarn into two layers along with finer count rather than regular denim.
\end{abstract}

\section{Keywords}

Denim, Double Cloth, GSM, Stiffness, Tensile Strength 


\section{Introduction}

Denim is a sturdy cotton warp-faced twill fabric that has acclaimed most popularity in the past three decades [1]. Although in 1969 a writer for American Fabrics magazine declared, "Denim is one of the world's oldest fabrics, yet it remains eternally young". Thermal insulation properties are very important from the point of view of thermal comfort of the clothing user as well as protective efficiency against low or high temperature [2]. Nowadays, researcher is trying hard to use denim fabric as a special purpose besides regular uses by enhancing comfort, thermal insulation and thickness. Undoubtedly, thermal comfort properties of textile materials have gained the attention of researchers in recent times [3]. When denim was introduced into the market, an attempt was made to produce cotton denim style using 100\% Polyester threads in 1980's period [1]. Considering the comfort factor, spandex is being used in denim but it cannot be covered all the requirements that is needed in winter-based country [4].

Double-layered weft knitted fabrics were designed for leisure sports with physiological and thermal comfort in mind whereas double cloth is designed for good thermal properties, appearance and feeling [5]. One layer (outer) was made from cotton yarns or man-made bamboo yarns and the (inner) was from synthetic fiber yarns (polypropylene, polyester and polyamide). The focal point of their research was to investigate the influence of knitting structure, fiber type, and yarn properties on the air and water vapor permeability of double-layered weft knitted fabrics [6]. Greyson and Havenith mentioned that heat and water vapor resistance increases with the increasing of thickness and air trapped in the fabric [7] [8].

Woven fabric multi-layer structure, the warp and weft densities, and the type of weave factors have a positive effect to transmit air, heat energy, and liquid perspiration [9]. With time being new fabric structure, based on double honeycomb fabric with self-stitching is developed. The honeycomb air pockets exhibit trap air and increase fabric thickness. For that the thermal comfort could be achieved. The results showed that the innovated structure had higher values of thermal insulation [10].

However, many researchers have immeasurable contribution to develop denim sector progress with concerning consumer demand. In conventional woven cloth, double cloth mechanism is currently using but no index journal has been found. However, most prior to known that there is no any comprehensive study were done on regular double cloth is previously. This is the new and innovative idea on denim for value addition and retention consumers to the denim market, also fulfillment the current consumer demand.

The aim of the study is to manufacture denim fabric in accordance with double cloth structure and checking the suitability in denim. In a boarder context, it will exhibit comfort feelings, thermal insulation property, and thickness. It may be used for winter season. It is noted with great concern that smoothness, softness and stiffness determine the physical and mechanical properties. Besides, 
it is easily compressible and bending fabric to be deemed soft, not stiff [11] [12] [13].

\section{Materials and Methods}

\subsection{Materials}

The experimental work was conducted in modern weaving laboratory at Dhaka University of Engineering and Technology (DUET), Dhaka, Bangladesh. The work has been accomplished by using $30^{\mathrm{s}} / 1$ and $20^{\mathrm{s}} / 1-100 \%$ cotton (CW) indigo dyed yarn (collected from Amber Denim Ltd, Gazipur, Bangladesh) and Polytex 17 (One-shot) as a sizing chemical. The yarn tenacity was tested by strength testing machine of Testometric Company with ASTM 2256-02 method (as shown in Table 1).

\subsection{Procedures}

Sample fabrics (50 inch $\times 15$ inch) were woven by a CCI (EVER GREEN 500) desk loom with electronic dobby shedding mechanism and rapier for weft insertion system. The warp sheet was prepared by a sample warping machine (SW 550) and sized with a sample sizing machine (SS 600). Before sizing, double cloth design has been developed by Textronics dobby CAD with three selected design. A movable machine is used to transfer held shaft, reed and weavers beam easily in loom after finishing the drawing and denting. Ironing is carried out and tested after desizing, enzyme wash. Figure 1 shows the specification of samples and simulations of CAD.

- Fabric construction $\left(\mathrm{R}_{1}\right): \frac{30 \times 30}{66 \times 35}+\frac{30 \times 20}{66 \times 35} ; 1 \mathrm{~F}: 1 \mathrm{~B}$

- Weave: $3 / 1$ warp $+3 / 1$ weft.

- Stitching point: 48 ends $\times 24$ picks.

- Fabric construction $\left(\mathrm{R}_{2}\right): \frac{30 \times 30}{120 \times 50}+\frac{30 \times 20}{40 \times 50} ; 3 \mathrm{~F}: 1 \mathrm{~B}$

Table 1. Sized yarn strength.

\begin{tabular}{ccc}
\hline \multirow{2}{*}{ SL No. } & 20 Ne indigo & 30 Ne indigo \\
\cline { 2 - 3 } & Tenacity (CN/Tex) & Tenacity (CN/Tex) \\
\hline 1 & 5.964 & 5.713 \\
2 & 6.354 & 5.551 \\
3 & 6.227 & 6.274 \\
4 & 5.89 & 6.094 \\
5 & 6.195 & 5.754 \\
Mean & 6.126 & 5.8772 \\
Max & 6.354 & 6.274 \\
Min & 5.89 & 5.551 \\
Standard Deviation $(\sigma)$ & 0.1726 & 0.2657 \\
\hline
\end{tabular}




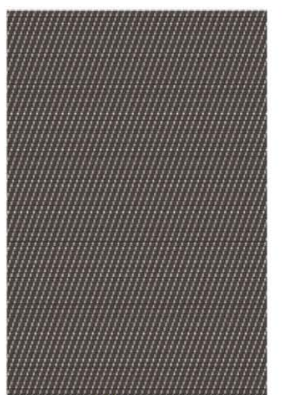

(a)

R1

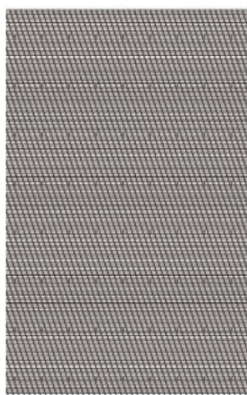

(b)

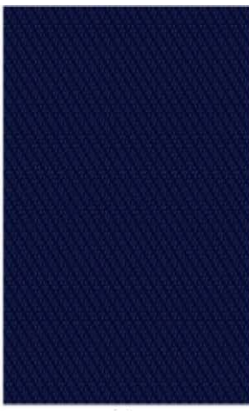

(a)

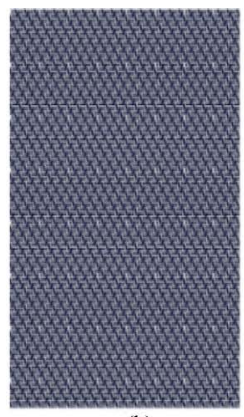

(b)

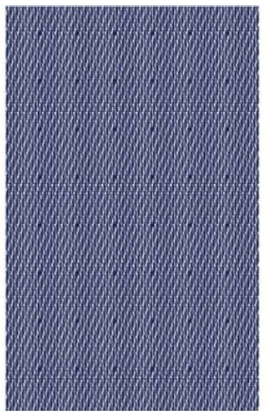

(a)

R2

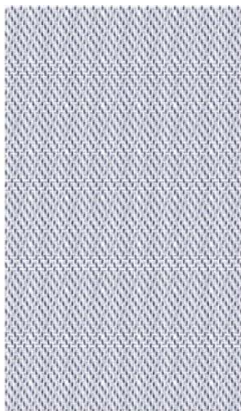

(b)

R3

Figure 1. CAD Simulation-(a) Face fabric; (b) Back fabric of sample.

- Weave: $3 / 1$ warp $+3 / 1$ weft.

- Stitching point: 48 ends $\times 24$ picks.

- Fabric construction $\left(\mathrm{R}_{3}\right): \frac{20 \times 30}{100 \times 50}+\frac{20 \times 30}{50 \times 50} ; 2 \mathrm{~F}: 1 \mathrm{~B}$

- Weave: $3 / 1$ warp $+3 / 1$ weft.

- Stitching point: 36 ends $\times 24$ picks

Figure 1 shows that the CAD simulation of all samples in face and back sides where R1, R2 and R3 indicates the developed double cloth samples. Face side of the sample is denoted by "a" and back side of the sample is denoted by " $b$ ".

\subsection{Methods}

All samples were tested according to ISO 139, under the standard testing conditions, i.e. temperature of $20^{\circ} \mathrm{C} \pm 2^{\circ} \mathrm{C}$ and $65 \% \pm 2 \%$ relative humidity ( $\mathrm{RH}$ ), and all samples were conditioned for at least $4 \mathrm{hrs}$ before test. The following method has been used namely ASTM D5034 for tensile (Grab) test by strength testing machine of Testometric Company; ASTM D3776-96(2002) methods for mass per unit area by GSM cutter; ASTM D1388-2007 for Stiffness tester by Shirley Stiffness tester.

\section{Results and Discussions}

\subsection{Assessment of Visual Appearance}

Usually double cloth fabric is a combination of two single layer fabric from two or more sets of warps and one or more sets of weft or filling yarns are interconnected by stitching. It is known that vertical twill sunken line will be visualized for denim fabric. The following manufactured samples are examined visually and compared with regular denim (as shown in Figure 2 and Figure 3), here it is found that the appearance of double cloth denim and basic denim is almost same.

\subsection{Assessment of Physical and Mechanical Properties}

The physical and mechanical properties of manufactured fabrics are affected by the fiber types, yarn construction and fabric structures, as well as any treatment 


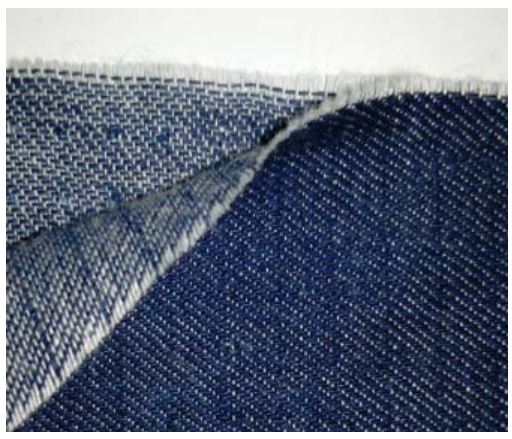

Figure 2. Visual appearance of double cloth.

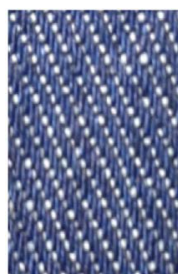

(a)

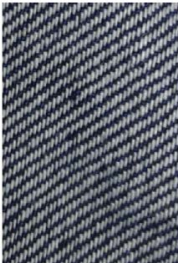

(b)

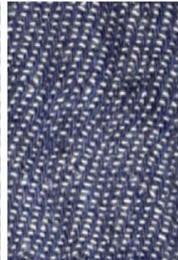

(a)

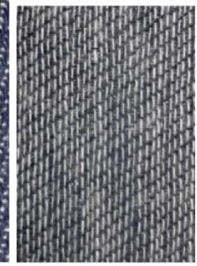

(b)

Single Layer

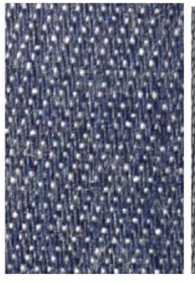

(a)

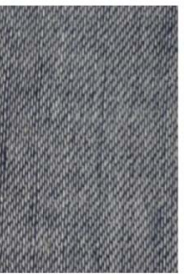

(b)

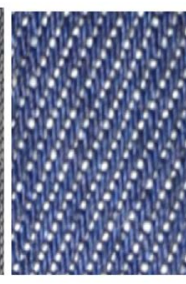

(a)

R1

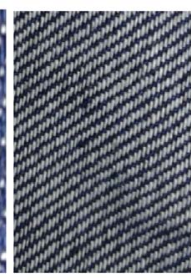

(b)

R2

R3

Figure 3. Visual appearance comparison-(a) Face side; (b) Back side.

that may have been applied to the materials. In case of double cloth, four important property has been tested such that weight (GSM), tensile strength, shrinkage and stiffness and after that compared with single layer denim (3/1 twill).

\subsubsection{Tensile Strength}

Generally tensile strength depends on yarn count, yarn strength, yarn crimp, weave construction, number of layers etc. Here, R1 rating has minimum and R3 rating maximum (as shown in Figure 4 and Figure 5). Although all samples are produced from same type yarn but result is not same. Here weave factor is major concern. It is known that if interlacement is more than strength will be more. In spite of the construction of Basic (3/1), R1 and R2 are same but strength is higher of basic (3/1). Because yarn spacing relatively is lower than R1 and R2. On the contrary, since yarns are dissipated into two layers in case of R3 but strength is greater than basic (3/1) structure. Because of that interlacement of yarn in fabric is high and total force is divided into two layers. So, R3 is suitable for double cloth denim. 


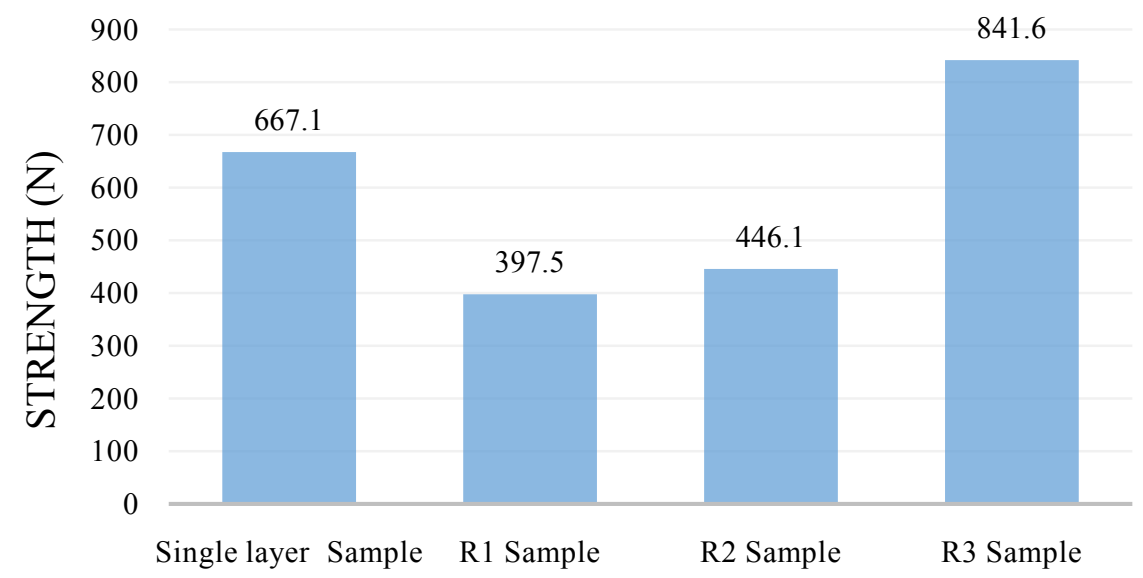

Figure 4. Warp way tensile strength chart.

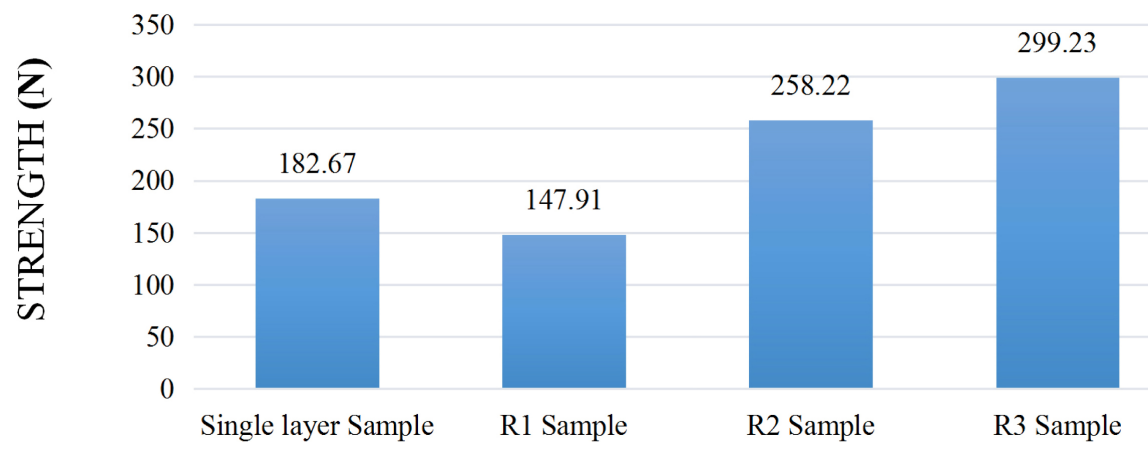

Figure 5. Weft way tensile strength chart.

\subsubsection{GSM or Fabric Weight}

In general conception, double cloth conveys high GSM. Although the developed samples are double denim but GSM is less than single layer (3/1) denim (as shown in Figure 6). However, the fabric could be single or double cloths but GSM totally depend on structures, EPI, PPI, warp count and weft count. Additionally, GSM could be preserved in double cloth denim by adjusting face and back fabric warp ratio, EPI, PPI and count of warp and weft yarn.

\subsubsection{Stiffness}

All knows that if bending length is high then fabric will be stiffer. In single denim fabric contain more bending length because of its compactness than double cloth denim, considering constant GSM for both. In double cloth denim warp and weft yarn are divided into two layer, so it will be form less compact resulting less bending length (as shown in Figure 7), the bending length is less than single layer denim (3/1). Since double cloth denim is less stiffness, so it will enhance softness and comfort ability on body.

\section{Conclusions}

Nowadays denim garment are most desirable and fashionable in the market. But it is not vastly applicable in all kind of garments (such as top samplers, child 


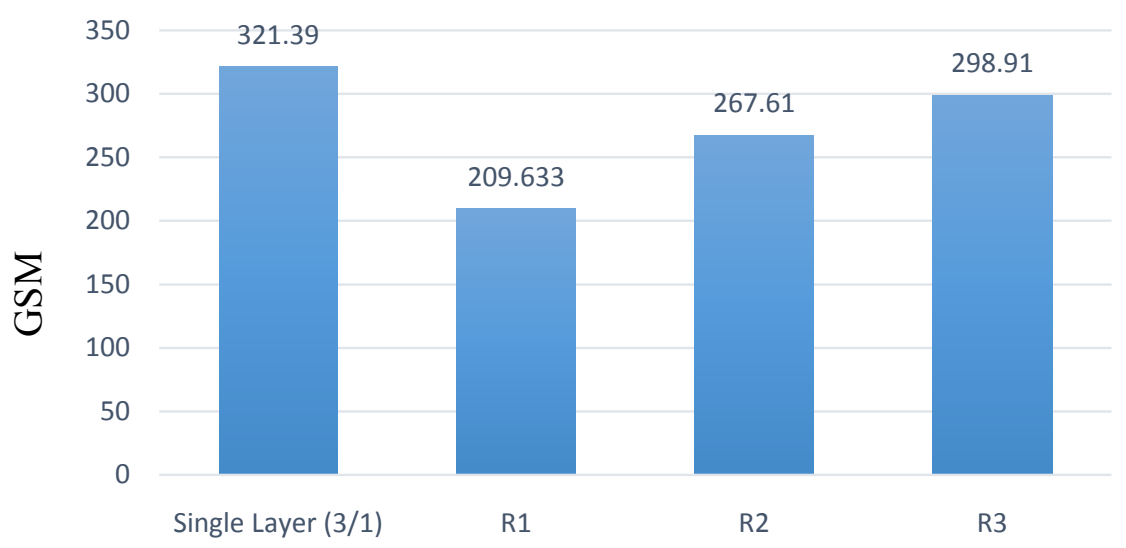

Figure 6. GSM test chart.

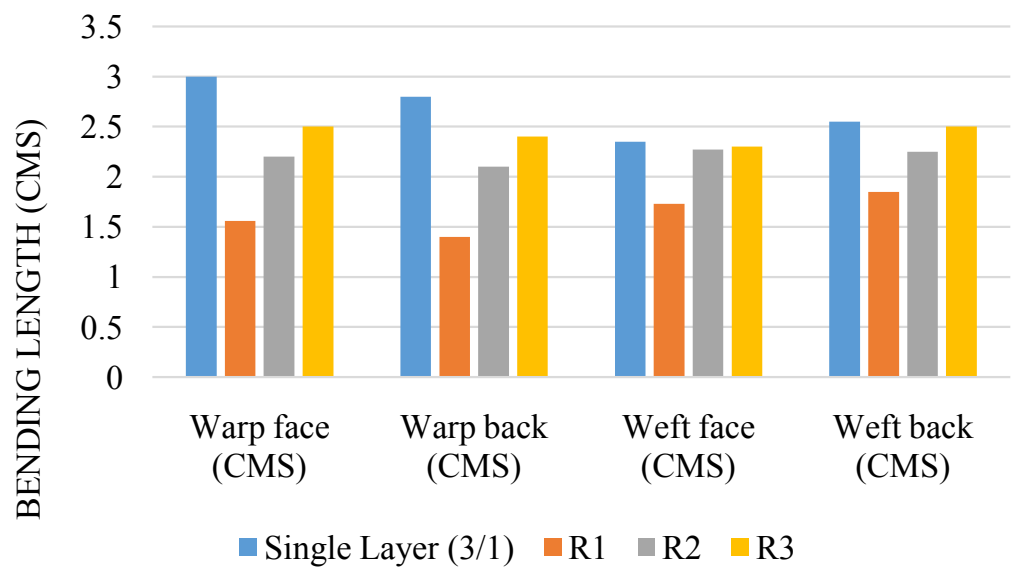

Figure 7. Stiffness test chart.

and ladies wear) because of less comfort ability and softness. So, in this study double cloth structure is applied in denim with few selected structures by $30^{\mathrm{s}} / 1$, and $20^{\mathrm{s}} / 1$ cotton yarn. Design is done by Textronics and samples are made by CCI sample loom in narrow width. Developed samples are washed (desize and enzyme). In the study three samples are developed and visual appearance, Tensile strength, GSM, Stiffness are tested. Test result shows that developed samples are more comfort (affects thermo-physiological comfort) than normal denim without any compromising of strength and GSM. In the meantime, other properties remain almost constant. This work shows that double cloth structure is possible in denim. In the developed double cloth denim, such limitations are kicked off and for this reason versatile application of double cloth denim can be possible and due to loosen structure (on bottom) exhibits comfort. Such versatile application like top garments, baby and kids wear, jacket, coat, cloth for winter season etc. vastly. Finally, it can say that double cloth structure may create new era in denim sector by satisfying consumer needs.

It is noted that, the double cloth structure of denim may be manufactured by cloth interchange technique, combination with indigo and reactive blue color yarn to found check effect after washing as well as various yarn types with various 
design derivatives can be applied as back fabric. Also, double cloth may exhibit more trapped air such honey comb weave in bottom layer.

\section{Author Contributions}

The whole work has been conducted under the supervision of $\mathrm{M}$. Z The objectives and methodology and also the samples manufactured of this works were proposed by R.A., N.H. and A.H. The specimen fabrication, characterization and testing carried out by R.A., N.H. and J.I. with the help of M.Z and T.I. The manuscript has been written by R.A. and finally revised by M.Z. and T.I.

\section{Conflicts of Interest}

The authors declare no conflicts of interest regarding the publication of this paper.

\section{References}

[1] Arjun, D., Hiranmayee, J. and Farheen, M.N. (2013) Technology of Industrial Denim Washing: Review. International Journal of Industrial Engineering \& Technology (IJIET), 3, 25-34.

[2] Matusiak, M. and Kowalczyk, S. (2014) Thermal-Insulation Properties of Multilayer Textile Packages. AUTEX Research Journal, 14, 299-307.

https://doi.org/10.2478/aut-2014-0030

[3] Majumdar, A., Mukhopadhyay, S. and Yadav, R. (2010) Thermal Properties of Knitted Fabrics Made from Cotton and Regenerated. International Journal of Thermal Sciences, 49, 2042-2048. https://doi.org/10.1016/j.ijthermalsci.2010.05.017

[4] Elnashar, E. (2016) Double Layer Denim Stretch Fitting Surfaces of Ancient Egyptian Clothes. Tekstilna Industrija, 1, 27-41.

[5] Gokarneshan, N. (2004) Fabric Structure and Design. New Age International (P) Ltd., New Delhi.

[6] Bivainyte, A., Mikucioniene, D. and Kerpauskas, P. (2012) Investigation on Thermal Properties of Double-Layered Weft Knitted Fabrics. Materials Scince (Medziagotyra), 2, 167-171.

[7] Greyson, M. (1983) Encyclopedia of Composite Materials and Components. Wiley \& Sons, Hoboken.

[8] Havenith, G. (2002) Interaction of Clothing and Thermoregulation. Exogenous Dermatology, 1, 221-230. https://doi.org/10.1159/000068802

[9] Elnashar, E. (2005) Volume Porosity and Permeability in Double-Layer Woven Fabrics. AUTEX Research Journal, 3, 207-218.

[10] Salama, A.A., El-Deeb, A.S. and El-Shahat, I.M. (2015) Evaluation of Bed Cover Properties Produced from Double Fabric Based on Honeycomb. Journal of Textiles, 2015, Article ID: 470456. https://doi.org/10.1155/2015/470456

[11] Ajayi, J.O. (1992) Fabric Smoothness, Friction, and Handle. Textile Research Journal, 62, 52-59. https://doi.org/10.1177/004051759206200108

[12] Elder, H.M., Fisher, S., Armstrong, K. and Hutchison, G. (1998) Fabric Softness. Handle and Compression. Journal of the Textile Institute, 75, 37-46. https://doi.org/10.1080/00405008408658459

[13] Elder, H.M. (1984) Fabric Stiffness. Journal of the Textile Institute, 75, 307-310. https://doi.org/10.1080/00405008408631708 